Parkinson's disease, depression, emotional problems, chronic alcoholism etc. But, Can the cellular phone irradiation be a cause of forgetfulness? This study was particularly designed to investigate the possibilities of association of the common symptom "forgetfulness" among the cellular phone users. The close proximity of the cellular phone to the head causes likely $40-60 \%$ energy emitted by the device to be absorbed in the brain. In this study 188 (77.7\% male and $22.3 \%$ female) cellular phone users in Lucknow city of India were enquired about the association of forgetfulness. They were enquired about their general profile (age, sex etc.), calls detail and health (disease, smoker or non-smoker). The subjects belonged to $14-62$ years age range (mean age \pm SD; $29.1 \pm 9.5$ ). Study revealed that $12.7 \%$ (14) subjects were associated to forgetfulness symptom. The frequency of forgetfulness among high user $(\mathrm{HU}>500 \mathrm{~h}$ use in life) and low user (LU $<500 \mathrm{~h}$ use in life) was found $2.1 \%$ and $10.6 \%$ respectively. In general it was found that the users, who held cellphone above the 4-5 years, were supplementary associated to the symptoms. This study supported by UP Council of Science and Technology, India. [Ref. CST/D 3558 (2); 31.03.2009].

\section{SP4-4 ANALYSIS OF KNOWLEDGE ABOUT ALCOHOL AND TOBACCO BY STUDENTS OF PHARMACY IN THE UNIVERSITY OF BARCELONA}

doi:10.1136/jech.2011.1429760.98

${ }^{1} \mathrm{~A}$ Pedrosa, ${ }^{*} \mathrm{C}$ Fonsêca, ${ }^{1} \mathrm{~A}$ Piranema. ${ }^{1}$ Faculdade de Medicina, Universidade Federal de Alagoas, FAMED/UFAL, Maceió, Alagoas, Brazil; '2Fundação Faculdade de Medicina, Universidade de São Paulo, FFMUSP, São Paulo, São Paulo, Brazil

Introduction It is well known that knowledge can change behaviours, thus introducing healthy habits or reducing the prevalence of risky habits. Based on this information, we studied the level of knowledge of students of Pharmacy in the University of Barcelona (Spain), concerning to the effects and diseases related to alcohol and tobacco.

Methods We analysed 178 students of both sex, between 18 and 27 years old. Data were obtained by applying a self-reported questionnaire.

Results The risk of ingestion of pure alcohol was considered such that practically no one consumed it. The students expressed low knowledge of the relationship between tobacco and bladder cancer (40.3\%), osteoporosis (29.9\%), and neonatal death (49.7\%). For alcohol the smallest percentages of knowledge were observed for the relationship between alcohol and sexual dysfunction (58.4\%) and endocrine-metabolic diseases (66.9\%). 25.9\% answered that the issue "tobacco as a risky factor to health" is insufficiently discussed or not discussed during the classes, and $41.6 \%$ answered the same about alcohol.

Conclusions In conclusion, about the risk of consumption of these drugs should be more emphasised by the university education.

\section{SP4-5 HEALTH CHECK-UP: CHANGES OCCUR IN MEDICAL REPORT}

doi:10.1136/jech.2011.1429760.99

${ }^{1} \mathrm{~A}$ Pedrosa, ${ }^{* 2} \mathrm{C}$ Fonseca, ${ }^{1} \mathrm{~L}$ Henrique, ${ }^{1} \mathrm{C}$ Guarino, ${ }^{1} \mathrm{~A}$ Neves, ${ }^{1} \mathrm{~A}$ da Silva, ${ }^{1} \mathrm{~A}$ Pedrosa. ${ }^{1}$ Faculdade de Medicina, Universidade Federal de Alagoas, FAMED/UFAL, Maceió, Alagoas, Brazil; ${ }^{2}$ Fundação Faculdade de Medicina, Universidade de São Paulo, FFMUSP, São Paulo, São Paulo, Brazil

Introduction Many disorders of the skin, mucous membranes, throat, ears and nostrils can be detected simply by visual examination doctor. The telltale characteristics include size, shape, colour and location of the anomaly. Any change of function or appearance can lead to important consequences for physical and mental health.

Objectives This research aims to identify the existence of medical and clinical changes related to various aspects, verifying the presence or absence of abnormalities, as well as the frequency of these.

Methods This study was done with students of the school children Francisco Melo of the neighbourhood Moacir Andrade and with children of the neighbourhood Santa Lucia, both in Maceió-AL, all assisted by Extension Project Santa Lucia/Tabuleiro Novo (PESLUTAN).

Results We analysed 88 children, of whom $45.5 \%$ were female. As for colour of skin and mucous membranes most were normal $(86.4 \%)$, only $1.1 \%$ it was hipercor and $12.5 \%$ pale. Of the total, $21.6 \%$ were using some kind of medication, had no physical defect, $14.8 \%$ had an umbilical hernia, $30.7 \%$ had mycosis, $11.4 \%$ were observed warts, $6.8 \%$ had oropharyngeal hyperaemia and $5.7 \%$ had hypertrophic tonsils. Regarding changes in the nasal cavity, $7.9 \%$ had turbinate hypertrophy, hyperaemia were $5.7 \%$ and $5.7 \%$ had nasal secretions. And as for normal hearing, $5.7 \%$ had abnormal hearing, $2.3 \%$ had otitis and $1.1 \%$ with otalgia.

Conclusion The results were quite impressive showing little change medical clinics, except only for fungal infections which accounted for $30 \%$, showing a distance of information about the personal hygiene of children.

\section{SP4-6 PHARMACEUTICAL WARNING: RECURRENT DISEASE IN THE COMMUNITY VILA SOMBRA DOS EUCALIPTOS}

doi:10.1136/jech.2011.1429760.100

${ }^{1} \mathrm{~A}$ Pedrosa, ${ }^{2} \mathrm{C}$ Fonsêca, ${ }^{1} \mathrm{~B}$ Queiroz, ${ }^{1} \mathrm{H}$ Nascimento, ${ }^{1} \mathrm{~J}$ Ferro, ${ }^{1} \mathrm{~J}$ Nascimento ${ }^{1} \mathrm{~K}$ Santos, ${ }^{1} \mathrm{~L}$ Silva, ${ }^{1} \mathrm{R}$ Ribeiro, ${ }^{1} \mathrm{~T}$ Silva, ${ }^{1} \mathrm{~V}$ Brito, ${ }^{1} \mathrm{~A}$ Pedrosa. ${ }^{1}$ Faculdade de Medicina, Universidade Federal de Alagoas, FAMED/UFAL, Maceió, Alagoas, Brazil; ${ }^{2}$ Fundação Faculdade de Medicina, Universidade de São Paulo, FFMUSP, São Paulo, São Paulo, Brazil

Introduction Epidemiologically, the theoretical model considers disease as a result of the aggression of a microorganism to an organisation and incorporates the concept of risk factor as the basis for the production of knowledge about preventive measures, useful in understanding the process and mechanisms of chronic nontransferable.

Objectives To obtain data about the most frequent diseases in the community, relating them to the indiscriminate use of medicines and to observe if that helps, harms and onset of symptoms than those originally presented.

Methodology Through home visits were conducted 80 interviews in the Vila Sombra dos Eucaliptos to collect data on prevalent diseases and to bring information to the community, ranging from pamphlets to Pharmaceutical Care.

Results Hypertension is undeniably the most common chronic recurrent in community, as well as nationally, followed by diabetes and flu. The poor conditions of hygiene and housing lead to a high rate of intestinal worms, especially among local children. While noting the high rate of self-medication, there was no direct relationship between the number of patients and the effects of the medication. Most patients considered more severe makes correct use of medicines prescribed by a doctor, not even making new appointments, thus not causing further damage to your health.

Conclusion The continuing occurrence of diseases at the community provides, among other factors, due the socio-economic conditions, structural conditions and the neglect of the relation Community vs Health Center-public agencies-primarily due to lack of medicines and basic assistance to the community. 